\title{
ALEGORÍAS REPUBLICANAS EN EL ÁREA LUPACA POR EL RECIBIMIENTO DE SIMÓN BOLÍVAR (1825)
}

\author{
REPUBLICAN ALLEGORIES IN THE LUPACA AREA \\ FOR THE RECEPTION OF SIMÓN BOLÍVAR (1825)
}

Elard Vladimir Chaiña Flores ${ }^{1}$

\begin{abstract}
RESUMEN:
Esta investigación se centra en la comprensión iconográfica de la decoración realizada para la visita de Simón Bolívar por tierras aimaras, por tanto, explora las alegorías de la naciente república peruana en el área Lupaca, en el actual departamento de Puno-Perú, específicamente en los pueblos de Chucuito, Acora, Ilave, Juli, Pomata y Zepita. Como el objetivo principal del presente trabajo fue la identificación, análisis e interpretación de la iconografía de las alegorías, se enmarca en la metodología de la investigación cualitativa y se concluye en que se idearon 7 escenas alegóricas inspiradas en la naturaleza; las cuales reflejan la idealización de la naciente república.
\end{abstract}

Palabras clave: Alegoría, iconografía, iconología, Lupaca, república.

\begin{abstract}
:
This investigation explores the allegories of the nascent Peruvian republic in the Lupaca area, in the current department of Puno - Peru; the iconography present in the decoration for the reception of Simón Bolívar in the towns of Chucuito, Acora, Ilave, Juli, Pomata and Zepita; The main objective was the identification, analysis and interpretation of the iconography of the allegories. This study focuses on the iconographic understanding of the decoration made for Simón Bolívar's visit to the Aymara lands; In this sense, it is part of the methodology of qualitative research and it is concluded that 7 allegorical scenes inspired by nature that reflect the idealization of the nascent republic were devised.
\end{abstract}

Keywords: Allegory, iconography, iconology, Lupaca, republic.

\footnotetext{
${ }^{1}$ Universidad Nacional Jorge Basadre Grohmann. Tacna-Perú. E-mail: ee01216@hotmail.com
} 


\section{INTRODUCCIÓN}

Esta investigación, que analiza e interpreta iconográficamente las alegorías planificadas para el recibimiento de Simón Bolívar en la provincia de Chucuito, contribuirá al conocimiento de la temprana iconografía republicana empleada en el ámbito Lupaca. Se postuló el supuesto de que las alegorías republicanas en el área aimara se desarrollaron de manera diversificada; planteándose como objetivo principal de estudio: identificar y describir las alegorías republicanas. Entre los factores importantes que motivaron la investigación, se tiene por un lado la concepción iconográfica de los pobladores en el contexto de la naciente república en el área de Lupaca y por otro, la inexistencia de registros escritos, visuales sobre este recibimiento.

En este sentido, el método iconológico permite una identificación preicónica y análisis iconográfico de las escenas alegóricas desde una perspectiva hermenéutica.

\section{METODOLOGÍA}

La investigación se enmarca dentro de la metodología de investigación cualitativa, centrándose en el análisis, interpretación y comprensión iconográfica de las tempranas alegorías republicanas planificadas para el recibimiento de Bolívar en 1825, en el área de Lupaca. El objeto de estudio está determinado por el siguiente análisis iconográfico: Primero, Identificación preiconográfica; Segundo, Análisis y comprensión iconográfica (Panofsky, 1987) del significado (imagen mental) del signo escrito (Peirce, 1986). Esto permitirá reflexionar, además, respecto a la visión del tiempo y espacio en que se manifiestan las alegorías objeto de estudio.

Los “recibimientos"

La amplia tradición establecida durante casi todo el periodo colonial hace que los recibimientos adopten características similares durante la república temprana. Esta "toma de posesión" o ritual de poder, que para Ortemberg (2016) representa la renovación del vínculo legitimizador entre el gobierno y el pueblo, comprende itinerarios tradicionales, actos de proclamación, juramentos, ritos litúrgicos, monumentos efímeros, alegorías, emblemas, estandartes, escudos, medallas, gestos simbólicos, diversiones populares, entre otros; en conjunto todo un hecho social, como el que se dio durante la entrada del virrey Morcillo a Potosí en 1786.

En las calles de Potosí se dispusieron dos arcos, cuadros alegóricos y colgaduras, [...] el programa de escenas alegóricas claramente inspirado en la emblemática moral, emblemas vivos o pintados, escogió específicamente tres conceptos o ideas alrededor de las cuales surgen otras. Estas tres son la Urbanidad, la Libertad y la Fama. (Querejazu, 2007, pp. 150-151)

Otro ejemplo fue la llegada del virrey Pezuela a Lima en 1816: "A la entrada del virrey, este fue conducido a una silla rectoral, ornamentada para la ocasión, que con el dosel, almohadillas y sobremesa tenía magnifica apariencia" (Bennett, 1971, p. 180). Así también ocurrió con el recibimiento de Bolivar, que no dista mucho del que ofrecían a los virreyes; Bolívar, después de su victoria de Ayacucho, recorrió victorioso desde el sur hacia el Alto Perú, con la constante de camaretas, repiques de campanas, arcos triunfales y demás agasajos; según relata Miller en su memoria:

Todo su viage había sido un triunfo continuado; á su proximidad á las capitales de los departamentos, los prefectos á la cabeza de las autoridades públicas, acompañados por gran parte de la población salían á su encuentro, y era recibido con una gran pompa y de alegría, muy agradable a su sentimientos, y correspondientes á su dignidad. Levantaron arcos triunfales, le hicieron ricos presentes, le dieron grandes comidas, bayles, y hubo corridas de toros en su obsequio. Los mismos honores aunque en escala menor le rindieron todas las villas y lugares por donde pasó. (1829, p. 268)

Este recorrido también fue mencionado por Haigh (1971): 
El general Bolívar proseguía su gira triunfal desde Lima al Alto Perú hasta Chuquisaca; acababa de dejar Arequipa, camino a Potosí; en todas partes se le recibía con honores principescos; en la entrada de cada ciudad se erigían arcos triunfales y damas de primer rango, vestidas de blanco, esparcían flores en el camino de su corcel cuando avanzaba. (p.49)

Ya en el Collao, José Domingo Choquehuanca arengó prodigiosamente a Bolívar (Puertas, 1943), sumando per se al aparato discursivo de toda la parafernalia del recibimiento. Los escasos registros del área de Lupaca solo nos permiten conocer las alegorías del recibimiento.
La alegoría

La alegoría proviene del griego allegorein que significa "hablar figuradamente", se trata de una idea, frase $u$ oración que posee un significado distinto al que se menciona; históricamente se entiende como una "figura o composición que emplean los pintores y escultores para expresar una idea abstracta, o espiritualizar ciertos actos de la vida humana, a fin de que su contemplación obre más poderosa y enérgicamente en el ánimo de los espectadores" (Ulloa et al., 1853, pp. 97-98). En la planificación del recibimiento de Bolívar en el área de Lupaca, Angelo Catacora contempla principalmente alegorías. (Tabla 1).

Tabla 1

Planificación para la recepción de Bolivar en los pueblos de Chucuito.

E.L.D.P.

Zepita marzo 26 de 1825

Al seffor general del Departamento

[Al margen] en todos los pueblos de la provincia regular recibimiento menos en Pomata, por las desavenencias de los curas.

Después de aber (sic) executado (sic) exactamente en los pueblos anteriores las comisiones que V.S. me ha conferido estoy en este último pueblo de la provincia, consultando de idear algo más de lo que previene en la instrucción y es como se sigue:

En la raya de Chucuito después de formado el arco triunfal, se presentarán dos toros de buena presencia mansos y decentemente vestidos en ambos costados, cada uno pisando el yugo opresor, y en seguida en el mismo pueblo de Chucuito, al pie del dosel y en ambos ex tremos de la silsa (sic) Poltrona dos águilas o buitres bien adornados con sintas (sic) de colores de Colombia y Perú.

En Acora dos garsas en la misma forma. En llave dos vicufias cargadas de barra tener de oro y plata.

En Juli dos venados con sus penachos muy enjoyados y sus escarapelas de Colombia

En Pomata dos llamitas pequeñas blancas para que resalten las cintas.

En Zepita dos alpaquitas pequeñas de un mismo color y tamaño. Todos estos animales ricamente vestidos. Si de U.V. Si parece conveniente desta su aprobación.

Dios guarde a V.S. muchos años Angelo Catacora.

Fuente: Archivo histórico de Puno: Fondo Prefectura. - transcripción paleográfica: Pilco Contreras, Néstor.

\section{RESULTADOS}

Se presenta la identificación preiconográfica y el análisis iconográfico de las alegorías para cada pueblo del área de Lupaca.

Tabla 2

Identificación preiconográfica de las alegorias.

\begin{tabular}{lllll}
\hline N $^{\circ}$ & Pueblos & Arquitectura efímera & Fauna & Accesorio - Ornamento \\
\hline 1 & Chucuito & Arco triunfal & Dos toros & Yugo \\
2 & Dosel y poltrona & Dos águilas o buitres & Cintas - colores de Colombia y Perú. \\
3 & Acora & & Dos garzas & Cintas - colores de Colombia y Perú. \\
4 & Ilave & & Dos vicufias & Barra de oro y plata. \\
5 & Juli & Dos venados & Escarapelas de Colombia \\
6 & Pomata & Dos llamitas - blancas & Cintas \\
7 & Zepita & Dos alpaquitas - mismo color y tamaño & \\
\hline
\end{tabular}

Fuente: Elaboración propia. 


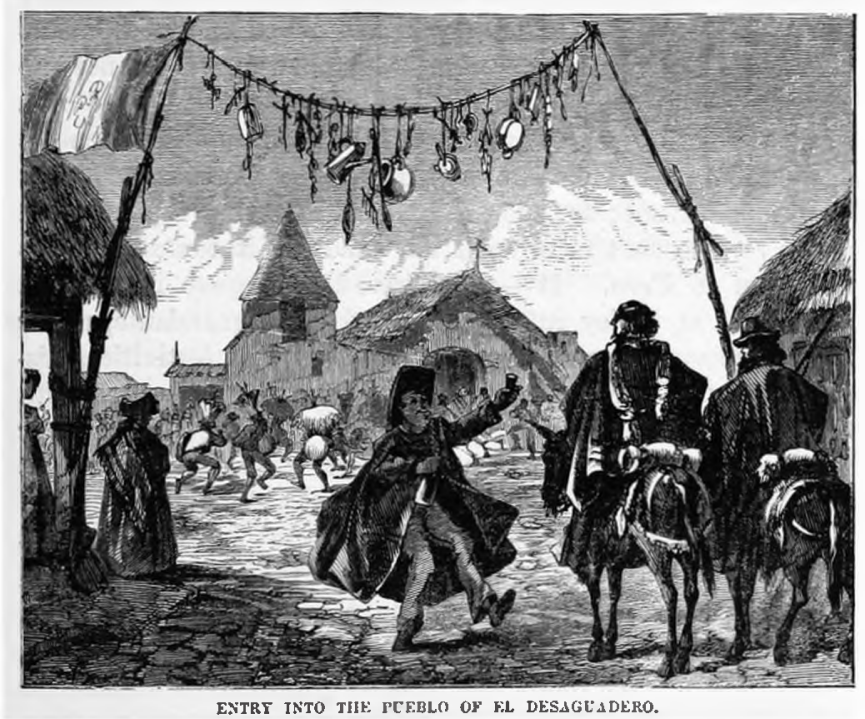

Figura 1. Arco en el pueblo de Desaguadero.

Fuente: Squier (1877, p. 351).

\section{Arquitectura efímera}

Heredada de la tradición colonial, aunque bajo el estilo neoclásico, los arcos triunfales (ver fig. 1) constituían el eje en torno al cual flanqueaban las alegorías vivas. Así mismo componían la arquitectura efímera, el dosel y "SILLA POLTRONA: silla más baja de brazos que la común, pero de más amplitud y comodidad" (Ulloa et al., 1861, p. 1112), silla griega y romana, la poltrona, se volvió a poner de moda durante el directorio, tal como lo explica Bennett:

... el interior más famoso de la época del Directorio fue diseñado por los Percier y Fontaine para Madame Récamier, una famosa belleza cuyo salón se convirtió en el lugar de reuniones de los dirigentes del nuevo régimen. El elegante diván de bellas proporciones, que se puede ver en el retrato de David, se realizó a partir del diserio de una poltrona griega. Enseguida se copió y convirtió en uno de los muebles más famosos de la época. Una de las versiones tenía respaldo.(1995,p. 138)

Fauna de las alegorías

Catacora menciona aves como los buitres en clara alusión al cóndor, ya registrado en 1612 por Bertonio (1956, p. 104 - I) "Bueytre. Contu$\mathrm{ri}^{3}$, denominación que perdura hasta 1837 ; al respecto, Salacroux (1837) sefiala lo siguiente: "EL GENERO BUITRE (vultur) [...] son de América, y llevan una especie de cresta carnosa en la base de su pico, como el condor ó gran buitre de los andes" (pp. 16,17), esto se debe, según menciona Claros (2012), a que "los primeros españoles les pusieron nombres usados en España por alguna semejanza [...]. Estas designaciones erróneas $y$, otras veces, arbitrarias han provocado imprecisiones, como el nombrar al cóndor por «buitre» o al puma «león»" (p.p. 179, 180); de igual forma sucede con la amplia clasificación de rapaces realizada por Bertonio (1956), que no precisa el género de águilas a las cuales se hace referencia en el documento, pudiendo ser el Allqamari de buen augurio - según supone Cereceda (2017)-, muy respetado por el poblador andino; las garzas también son mencionadas, pero sin mayor relevancia para el poblador de Lupaca.

Así también se hace mención a mamíferos auquénidos como las vicuñas, muy apreciadas por la finura de su fibra:

cúbrele el cuerpo una lana finísima de color rosa seca, capaz de admitir muy bien todo género de tintes artificiales y de la cual hacen en los departamentos 
del Perú muy buenos pañuelos, medias guantes, sombreros \&c. esta lana ya es bien conocida y estimada en Europa, y de ella hacen paños bien finos [...]. El hombre de nuevo mundo, el grande, el inmortal libertador Simón Bolívar espidió dos decretos relativos a las vicunas: por el primero prohibía su matanza, y por el segundo ofrecía un premio al que llegase a domesticarlas. (Anónimo, 1837,p. 8)

Decretos emitidos el 5 de julio de 1825 , Número 133. "Se prohíbe su matanza, y solo puedan trasquilarse [...]. Premio al que reúna rebaño de mansas, en el término que se designa" (Decretos, 1832, p. 132).

Las llamas y alpacas que constituyeron fuente de riqueza (Diez de San Miguel, 1964), (Gutiérrez, 1964), de su lana se produjeron tejidos que cumplieron funciones económicas, sociales y políticas en sociedades comunitarias y estales (Murra, 1975), (Flores, 1977). Su amplia terminología textil fue registrada por Bertonio (1956), sistematizada por Yapita Arnold y Aguilar (2014), y ampliamente estudiada por Gisbert, Arce y Cajías (2006); lo que da cuenta de la importancia de los auquénidos en el contexto puneño.

La tradición oral, registros escritos y representación plástica del venado es escasa en el altiplano puneño; excepcionalmente los cuernos son utilizados como medicina popular (Narváez, 2012), llamado taruca o tarukha por Bertonio (1956).

Los toros asimilados por la cultura andina causaron admiración a propios como a extraños, principalmente por sus lidias (Motta, 1989) y por sus peculiaridades (Marcoy, 2001).

\section{Accesorios y ornamentos}

Complementando a la fauna, los accesorios y ornamentos configuran el aparato discursivo de las alegorías. E1 yugo representa “... La ley y dominio superior que sujeta y obliga a obedecer. [...] SACURDIR EL YUGO: salir de alguna pesada sujeción, dominio u otra cosa que servía de peso, gravamen o molestia" (Ulloa et al., 1861, p. 1374).
A la llegada de Bolívar a territorio peruano, ya se usaban los colores de Colombia y Perú; por ejemplo, el teatro de Lima “... estaba toda adornada con los colores colombianos, y sobre el palco presidencial inmediatamente en el centro del orden más bajo, estaban las banderas entrelazadas del Perú y Colombia" (Proctor, 1971,p. 265), usándose en cintas estos mismos colores en el aérea de Lupaca; por otro lado, la riqueza se representó con barras de oro y plata.

\section{DISCUSIÓN}

Desde la rebelión de Túpac Amaru, los sucesivos conflictos sociales en el Altiplano, tanto como las ingentes cantidades de recursos que estos utilizaron, mermaron la economía de la región. Tamayo (1982) afirma: "Entre 1780 y 1783, empezaría el período de la decadencia demográfica, económica y ganadera de Puno que duraría prácticamente hasta 1830 , es decir se inició un ciclo de 50 años" (p. 70). Dichos conflictos ocasionaron:

La destrucción de la propiedad acompañó a la despoblación del Altiplano. El daño más duradero a la base de la economía [...] se cometió al diezmarse los rebaños de ganado. Ovejas, vacas y animales de transporte fueron requisados por ambos ejércitos en cualquier hacienda que cayera cerca de su camino. (Jacobsen, 2013, p. 93)

Toda acción bélica implicaba una destrucción de los recursos económicos del Altiplano y para comienzos del siglo XIX, el escenario es como Domínguez(2017) describe:

La intensidad de la represión colonial de 1810-1816 y la presencia de un poderoso ejército realista en el Alto Perú desde 1813, reforzado además con el traslado al Cuzco a fines de 1920 del virrey La Serna (1820-1824), ayudan a entender que el Sur Andino se mantuviera "pacificada" durante las Campañas Libertadoras de San Martín (1820-1822) y de Bolívar (18231826).(P. 263)

Después de la batalla de Ayacucho "El general Miller fue nombrado prefecto y comandante 
general del departamento Puno, a donde llegó el cuatro de febrero" (Miller, 1829, p. 207); posteriormente "Bolívar arribó a Puno el 5 de agosto de 1825 [...] de paso a La Paz. El general Miller prestó particular atención al departamento de su mando"(Romero, E., 1928, p. 45).

El movimiento social de Túpac Amaru, de Pumacahua, así como las campañas libertadoras generaron una precaria economía en la región "pacificada" del Altiplano. Después de 1781 se eliminaron muchos cacicazgos rebeldes y el 4 de julio de 1825, Simón Bolívar abolió el cargo de cacique, lo que relegó definitivamente la reivindicación incásica. Los criollos coparon estos espacios y fue desde su visión, que se generó todo el aparato discursivo republicano.

Las alegorías o configuraciones iconografícos producidas por los hombres sirven para intercambiar conocimientos, sentimientos y experiencias; asimismo para organizar un sistema de vida social en base a las ideologías, costumbres, leyes y tradiciones. Estas tempranas alegorías republicanas se configuraron bajo el espíritu de la ilustración adoptada por los patriotas locales, por ejemplo la logia "Independencia del Perú" fundada por Santa Cruz en 1829 en Zepita, es conformada — según Teresa Gisbert (2006, p. 184) - por puneños: “. ... de los nueve firmantes cinco eran puneños y uno boliviano, todos ellos con sobrenombres relacionados con los incas o la antigüedad clásica ...", esta mentalidad ilustrada con corporeidad estética neoclásica fue lo que permitió el desarrollo de alegorías basadas en la naturaleza. Establecidas ya en el escudo peruano de 1825:

$1^{\circ}$ Las armas de la Nación Peruana constarán de un escudo dividido en tres campos: uno azul celeste a la derecha, que llevará una Vicuña mirando al interior; otro blanco a la izquierda, donde se colocará el árbol de la Quina, y otro rojo inferior, y más pequeño, en que se verá una Cornucopia derramando monedas, significándose, con estos símbolos, las preciosidades del Perú en los tres reinos de la naturaleza. (Ponz, 1974, p. 25)

La mayoritaria presencia criolla en la independencia desplazará simbólicamente al emblema del sol y a las montañas de los incas, por esta
“... línea emblemática que, liderada por Unanue, habría de imponerse luego en los símbolos que finalmente serían adoptados para representar la nación" (Majluf, 2006, p. 220); o como sentencia Ortember (2016): "la elite impuso finalmente un "sentimiento patrio naturalista»" (p. 348).

Esta visión naturalista propuesta por Catacora, compuesta principalmente por una fauna nativa como el águila o el cóndor, con un casi nulo registro prehispánico en contraste con su amplia mención en el folklor contemporáneo según refieren Millones y Mayer (2012), "pareciera haber tomado una nueva vida en los siglos XIX, tanto es así que pertenece de manera explícita al imaginario criollo. Para darnos cuenta de ello basta mirar los escudos en las banderas de Bolivia y Chile" (p. 92). Bajo esta misma premisa se encuentran las garzas: aves lacustres muy valoradas en Europa por su plumaje (Salacroux, 1837); no obstante, sin mayor importancia para el poblador aimara.

Otro ejemplo se encuentra en auquénidos como las llamas, alpacas y principalmente la vicuña; esta última valorada no solamente por su utilidad sino también por representar la libertad:

Su utilidad para el comercio de hecho la hacía más atractiva que el cóndor para expresar la riqueza de su fauna local. Pero además, la vicuña evocaba otra esfera de asociaciones. A diferencia de la llama, no se presta al servicio de la carga, recorre con independencia las punas y se resiste a la captura y a la domesticación. (Majluf, 2006,p. 233)

Estos atributos de libertad, agreste y hasta salvaje, los posee asimismo el venado. Para Bertonio (1956), Tarukha está relacionado con lo salvaje: "Taruja jaqi. Descorazonado, hombre salvaje, que no sabe tratar con nadie, rústico. Tarujaptaña. Volverse salvaje el que trataba bien con todos" (p. 635); y aunque no forma parte de la fauna nativa, los toros fueron asimilados perfectamente por la cultura andina, los cuales, sumados al yugo generan su propio discurso simbólico.

Estas alegorías basadas en la riqueza de la naturaleza también estuvieron representadas por 
minerales como el oro y la plata. La inexistente representación de la flora denota su situación poco privilegiada en el Altiplano; contrastando con la exuberante vegetación del antisuyo representada en los templos en alusión al paraíso (Gisbert, 2001).

Por lo tanto, la concepción de estas tempranas alegorías en el área de Lupaca no seguirán la línea iconográfica de América, imagen femenina, voluptuosa y bárbara (Gravelot y Cochin, 1866), para acabar convertida en la madre patria (Soux, 2013); sino que estarán claramente inspiradas en la emblemática natural, con lo que Majluf (2006) también coincide: "señalaban una visión utilitaria de la naturaleza como factor de desarrollo científico económico, que había sido compartida por un amplio circulo de ilustrados americanos"' (p. 233).

Estas alegorías de la riqueza natural como la fauna, son complementadas con accesorios y ornamentos que flanquean el arco triunfal bajo el nuevo estilo republicano y aunque el "... neoclasicismo pierde su rigor académico en el altiplano puneño" (Chaiña, 2015, p.14) configuran las alegorías previstas: en Chucuito dos toros decentemente vestidos, pisando el yugo "símbolo de servidumbre, sometimiento e incluso humillación ..." (Revilla, 1995, p. 433), en clara alusión a la independencia del yugo Español; al pie del dosel flanqueando la silla poltrona se encontraban dos águilas o cóndores con las cintas de colores de Colombia y Perú. En Acora las garzas, seguramente ornamentadas con las cintas de colores de Colombia y Perú, debieron flanquear el arco triunfal; puesto que Bolívar se encontraba de paso. En Ilave las vicuñas cargadas de barras de oro y plata conjugan la riqueza natural de fauna y mineralogía; los dos venados con la cornamenta enjoyada y las escarapelas de Colombia en Juli. En Pomata estaban previstas dos llamas blancas con cintas; sin embargo, no llegaron a concretizarse por las desavenencias con los curas, como lo manifiesta Catacora. En Zepita se recrearon alpacas, sin mayor atributo mencionado.

Todo este aparato discursivo pertenece al periodo de formación y maduración de la modernidad europea, marcado por la ilustración. Este constante flujo de ideas, imágenes y personas entre el centro y la periferia se produce desde la perspectiva de la elite local; en el caso de Lupaca, con lenguajes vinculados y dependientes.

\section{CONCLUSIONES}

Tras la desolación económica, social, política y cultural del Altiplano - generada por sucesivas convulsiones sociales- era recibido en Puno, el 5 de agosto de 1825, Simón Bolívar en su tránsito a Potosí; de ahí seguiría camino por todo el área de Lupaca. A fin de recibir al libertador y como parte de los rituales de poder propio de su envestidura, en estos pueblos se habían planificado alegorías, las cuales fueron ideadas por criollos ilustrados locales cuyo aparato discursivo desplazaba la iconografia de reivindicación inca en favor de una emblemática naturalista, bajo el influjo de la ilustración.

Se concluye que siguiendo la línea emblemática nacional, se idearon para el recibimiento de Simón Bolívar siete (7) escenas alegóricas claramente inspiradas en la emblemática natural, compuesta principalmente por una fauna nativa: aves como el águila o el cóndor propio del imaginario criollo, garzas sin mayor importancia para el poblador aimara. Los auquénidos como llamas, alpacas y principalmente vicuñas, valoradas por su utilidad y por representar la libertad. El venado o Tarukha, libre, agreste y hasta salvaje; y los toros pisando el yugo, cada uno con su propio discurso simbólico. Los minerales, conformado por oro y plata; con referencia a la flora se carece de alegorías, lo que es muestra de su condición poco privilegiada en el Altiplano.

Las alegorías denotan la riqueza natural como factor de desarrollo científico y económico, visión compartida por la elite local de la naciente república en el área de Lupaca.

\section{REFERENCIAS BIBLIOGRÁFICAS}

Anónimo.(1837). La vicuña. Periódico - Museo erudito o los tiempos y las costumbres. No 9. Cuzco. Julio 15 de 1837. Cuzco: Imprenta Literaria por Juan Bautista.

Bennett, P. (1995). Historia dibujada del mueble occidental. Madrid: Celeste Ediciones.

Bennett, W. (1971). [1829] Memorias de W.B.S. sobre las campañas de San 
Martín y Cochrane en el Perú. Relación de viajeros. Volumen $3^{\circ}$ - Colección documental de la independencia del Perú. Tomo XXVII. Lima: Comisión Nacional del Sesquicentenario de la Independencia del Perú.

Bertonio, L. (1956). [1612] - Vocabulario de la lengva aymara. La Paz Bolivia: Litografía Don Bosco.

Cereceda, V. (2017). A partir de los colores de un pájaro. De los ojos hacia el alma. La Paz: Plural Editores.

Chaiña, E. (2015). Del kero colonial al kero republicano. La vida \& la historia. UNJBG Tacna, 1(4), 7-18.

Claros, E. (2012). Fauna y flora en e1 Vocabvlario de la lengva aymara de Ludovico Bertonio. Ciencia y Cultura. UCBSP, 1(28), 175-216.

Decretos (1832). Colección de leyes, decretos y órdenes publicadas en el Perú desde su independencia en el año de 1821, hasta 31 de diciembre de 1830, Tomo 2. Lima: Imprenta de José Masías.

Domínguez, N. (2017). Aproximaciones a la historia de Puno y del Altiplano. Puno: Ministerio de Cultura-Perú.

Flores, J. (1977). Pastoreo, tejido e intercambio. En Pastores de Puna - uywamichiq punarunakuna. Lima: IEP.

Gisbert, T., Arce, S. \& Cajías, M. (2006). Arte textil y mundo andino. $3^{\circ}$ ed. La Paz: Plural Editores.

Gisbert, T. (2001). El paraíso de los pájaros parlantes - La imagen del otro en la cultura andina. $2^{\circ}$ ed. La Paz: Plural Editores.

Gisbert, T. (2006). Iconografía mitológica y masónica a fines del virreinato e inicios de la república. En Visión y símbolos del virreinato criollo a la republica peruana. Lima: BCP

Gutiérrez, P. (1964) [1574]. Padrón de los mil indios ricos de la provincia de Chucuito y de los pueblos, parcialidades de la tierra que cada uno tiene. En Visita hecha a la provincia de Chucuito por Garci Diez de San Miguel en el año 1567. Lima: Casa de la Cultura del Perú.

Gravelot. \& Cochin. (1866). [1791] Iconología o tratado de alegorías y emblemas - obra traducida al castellano y anotada por el
Lic. Don Luis G. Pastor. Tomo I. México: Imprenta Económica.

Haigh, S. (1971). [1829] Bosquejos de Buenos Aires, Chile y Perú. Relación de viajeros. Volumen $3^{\circ}$ - Colección documental de la independencia del Perú. Tomo XXVII. Lima: Comisión Nacional del Sesquicentenario de la Independencia del Perú.

Jacobsen, N. (2013) Ilusiones de la transiciónEl altiplano peruano, 1780 -1930. Lima: Editorial del Instituto de estudios Peruanos.

Majluf, N. (2006). Los fabricantes de emblemas. Los símbolos nacionales en la transición republicana. Perú, 1820 1825. En Visión y símbolos del virreinato criollo a la republica peruana. Lima: BCP

Marcoy, P. (2001). [1869] Viaje a través de América del sur-Del océano Pacífico al océano Atlántico. Tomo I. Lima: IFEA PUCP-BCRP-CAAAP.

Miller, J. (1829). Memorias del general Miller al servicio de la república del Perú. Londres: Carlos Wood e Hijo.

Millones, L. y R. Mayer. (2012). La fauna sagrada de Huarochirí. Lima: IEP IFEA.

Motta, E. (1989). El astero de plata. Anthropologica. Año VI. No 6. Lima: PUCP.

Murra, J. (1975). Formaciones económicas y políticas del mundo andino. Lima: IEP

Narváez, A. (2012). El venado en 1a cosmovisión andina. Animales de Dios. Lima: Fondo Editorial de la Asamblea Nacional de Rectores.

Ortemberg, P. (2016). Rituales de poder en Lima (1735-1828) De la monarquía a la república. 2da Ed. Lima: Fondo Editorial - Pontificia Universidad católica del Perú.

Panofsky, E. (1987). El significado en las artes visuales. Cuarta reimpresión. Madrid: Alianza Forma.

Peirce, Ch. (1986). La ciencia de la semiótica. Buenos Aires: Nueva Visión.

Ponz, G. (1974). Símbolos de la patria.Colección documental de la independencia del Peru. Tomo X. Lima: Com is ión $\mathrm{N}$ a cional de 1 
Sesquicentenario de la Independencia de la República.

Proctor, R. (1971). [1825] De narración del viaje por la cordillera de los Andes y residencia en Lima, y otras partes del Perú, en los años 1823 y 1824 . Relación de viajeros. Volumen $2^{\circ}$ - Colección documental de la independencia del Perú. Tomo XXVII. Lima: Comisión Nacional del Sesquicentenario de la Independencia del Perú.

Puertas, N. (1943). José Domingo Choquehuanca. Lima: Universitas.

Querejazu, L. (2007). El programa emblemático alegórico en la entrada del virrey Morcillo a Potosi en 1716. La Fiesta - Memoria del IV encuentro internacional sobre barroco. La Paz: Unión Latina.

Revilla, F. (1995). Diccionario de iconografia y simbología. Madrid: Catedra.

Romero, E. (1928). Monografía de1 departamento de Puno. Lima: Imprenta Torres Aguirre.

Salacroux. M. (1837). Nuevos elementos de Historia Natural, conteniendo la zoología, la botánica, la mineralogía y la geología, aplicadas a la medicina, a la farmacia a las ciencias y artes comunes. Tomo II. Madrid: Imprenta de Verges.

Soux, M. (2013). De la América bárbara a la Patria ilustrada: Alegorías de América, la igualdad y el mito del buen salvaje. Estudios Bolivianos, 1(19), 95-118.

Squier, G. (1877). Peru: incidents of ravel and exploration in the Land of the Incas. New york: Harper \& Brothers, Publishers

Tamayo, J. (1982). Historia social e indigenismo en el altiplano. Lima: Trenta y trés.

Ulloa, A. y otros. (1853). Diccionario enciclopédico de la lengua española, con todas las vozes, frases, refranes y locuciones usadas en España y las Américas españolas, en el lenguaje común antiguo y moderno; las ciencias, artes y oficios; las notables de la historia, biografía, mitolojia y geografía universal, y todas las particularidades de las provincias españolas y americanas.
Tomo I. Madrid: Gaspar Roig Editores.

Ulloa, A. y otros. (1861). Diccionario enciclopédico de la lengua española, con todas las vozes, frases, refranes y locuciones usadas en España y las Américas españolas, en el lenguaje común antiguo y moderno; las ciencias, artes y oficios; las notables de la historia, biografía, mitolojia y geografía universal, $\mathrm{y}$ todas las particularidades de las provincias españolas y americanas. Tomo II. Madrid: Gaspar Roig Editores.

Yapita, J., Arnold, D. \& Aguilar, M. (2014). Los términos textiles aymaras del siglo XVIII de la región lacustre Vocabulario semántico según la cadena productiva. La Paz: ILCA. 